\title{
Treatment Satisfaction Among Patients Using Anti-Inflammatory Topical Medications for Dry Eye Disease
}

This article was published in the following Dove Press journal: Clinical Ophthalmology

\author{
Darrell E White' \\ Yang Zhao ${ }^{2}$ \\ Hemalatha Jayapalan (1D ${ }^{3}$ \\ Pattabhi Machiraju ${ }^{3}$ \\ Ramu Periyasamy ${ }^{3}$ \\ Abayomi Ogundele ${ }^{2}$ \\ 'SkyVision Centers, Westlake, OH, USA; \\ ${ }^{2}$ Sun Pharmaceutical Industries, Inc., \\ Princeton, NJ, USA; ${ }^{3}$ Indegene, Inc., \\ Bangalore, India
}

Correspondence: Abayomi Ogundele Medical Affairs, Sun Pharmaceutical Industries, Inc., 2 Independence Way, Princeton, NJ 08540, USA

Email abayomi.ogundele@sunpharma.com
Purpose: To assess patient satisfaction among current and former users of the antiinflammatory topical medications, cyclosporine A $0.05 \%$ (CYC) and lifitegrast $5.0 \%$ (LIF), for the management of dry eye disease (DED).

Patients and Methods: Patients with DED were recruited via physician referral to participate in a survey. Current users of CYC or LIF were asked to rate their experience in terms of satisfaction, side effects, and limitation of activities. Switchers of CYC to LIF or LIF to CYC were asked to rate the importance of potential reasons for switching.

Results: Surveys were completed by 207 patients currently treated with CYC (n=98), LIF $(n=96)$, or other DED medications $(n=13)$. Although overall satisfaction with current treatment was high, current users of CYC and LIF reported ineffective relief of DED symptoms (31\% and $22 \%$, respectively) and dissatisfaction with the time to onset of effect ( $29 \%$ and $11 \%)$. Substantial proportions of patients reported 'sometimes', "usually", or 'always' experiencing the following side effects: burning sensation ( $72 \% \mathrm{CYC}, 64 \% \mathrm{LIF})$, itching (43\% CYC, 44\% LIF), altered sensation of taste (21\% CYC, 56\% LIF), blurred vision (37\% CYC, $50 \%$ LIF), and discharge (28\% CYC, 30\% LIF). Of the 30 switchers of CYC to LIF and 31 switchers of LIF to CYC, the majority reported inability to relieve DED symptoms as a very or extremely important switching reason. Despite switching, one in four patients were somewhat dissatisfied or dissatisfied with their current medication, with $37 \%$ of patients reporting ineffective symptom relief.

Conclusion: Although the rate of overall satisfaction was generally high with both LIF and CYC, many patients were unable to achieve effective symptom relief and commonly experienced side effects. The proportion of patients who were dissatisfied and/or unable to achieve effective symptom relief even after switching suggests the need for additional treatment options for managing DED.

Keywords: patient satisfaction, dry eye disease, cyclosporine, lifitegrast, ocular surface

\section{Introduction}

Dry eye disease (DED) is a chronic, multifactorial, progressive condition estimated to affect around 16 million adults in the United States (US) alone, ${ }^{1}$ and with a global prevalence of between $5 \%$ and $34 \% .^{2}$ DED is more common among women than men, and prevalence increases with age. ${ }^{1}$ Other risk factors for DED include wearing contact lenses, prolonged screen time, hormonal changes, autoimmune disease (e.g. Sjögren's syndrome), environmental conditions such as low humidity and pollution, and use of systemic medications that may affect tear 
production and secretion. ${ }^{3}$ Ophthalmic and eyelid surgeries and post-procedural medications can also trigger DED. ${ }^{3}$ Presenting symptoms vary between patients but commonly include ocular discomfort, visual disturbances, and dryness that requires long-term treatment. ${ }^{3,4}$

Quality of life (QoL) outcomes are a core component of dry eye research and are of major importance to patients. ${ }^{5}$ DED has been shown to contribute to limitations in daily activities such as using a computer, reading, and driving, ${ }^{6}$ and also has detrimental effects on sleep ${ }^{7}$ and work productivity that increase with the severity of symptoms. ${ }^{8,9}$ Thus, the goal of treatment in DED is to relieve symptoms and improve QoL by restoring normal homeostasis in the tear film and ocular surface. ${ }^{10}$ Treatment options include artificial tears, topical anti-inflammatory agents, immunosuppressants, and antibiotics. ${ }^{10,11}$

Only two topical anti-inflammatory agents for DED are approved and commercially available in the US. Cyclosporine ophthalmic emulsion $0.05 \%$ (CYC) was approved in 2003 for increasing tear production in patients with reduced tear production presumed due to ocular inflammation. ${ }^{12}$ Lifitegrast ophthalmic solution 5\% (LIF) was approved in July 2016 for the treatment of signs and symptoms of DED. ${ }^{13}$ The 2019 American Academy of Ophthalmology guidelines discussed both drugs as treatment options for the management of patients with dry eye. ${ }^{14}$ For both drugs, the most common side effect is a burning or stinging sensation upon instillation, ${ }^{15,16}$ and this outcome together with ocular discomfort and ocular pain has been identified in a global Delphi survey as being most important to patients with dry eye. ${ }^{5}$ Dysgeusia is a unique side effect of LIF, occurring in $14.5 \%$ of patients randomized to receive this therapy across five clinical trials. ${ }^{16}$

To date, few studies have assessed patient satisfaction with CYC and there are no published data on patient satisfaction with LIF. ${ }^{17-19}$ The largest of the studies in CYC was a 2006 survey of 3145 DED patients in the US, which reported high treatment satisfaction and willingness to continue treatment among the $79 \%$ of patients who adhered to the prescribed twice-daily dosing. ${ }^{18}$ In an open-label extension of the CYC Phase III clinical trials, $95 \%$ of patients reported that they would continue using CYC and $98 \%$ would recommend it to others with DED. ${ }^{17}$ One concern for patients taking CYC is that the onset of efficacy can take 3-6 months. ${ }^{17}$ LIF tends to work more rapidly, with significant improvements from baseline evident after as little as 2 weeks. ${ }^{20}$ However, in one study $47.3 \%$ of patients treated with LIF over 12 months experienced side effects considered possibly or probably drug-related, resulting in the discontinuation of LIF in $12.3 \%$ of patients. ${ }^{21}$

The primary objectives of this study conducted among patients with DED in a real-world setting were to assess treatment satisfaction among current users of CYC or LIF, and to assess reasons for treatment change among former users of CYC and LIF.

\section{Materials and Methods Study Design and Patient Population}

This was a cross-sectional survey study conducted between October 2018 and January 2019 at 20 centers in the US. Twenty-one physicians currently treating DED patients with CYC and LIF were invited to refer patients eligible to take part in the survey. Participating patients were able to access the surveys via a secure web-based link and could complete the survey in intervals to reduce the burden of fatigue. The patient survey was codeveloped with clinicians. This study was Health Insurance Portability and Accountability Act (HIPAA) compliant, approved by an institutional review board (Sterling Institutional Review Board, Atlanta, Georgia), and conducted in accordance with the Declaration of Helsinki.

Patients with a diagnosis of DED who were current or recent users of either CYC or LIF were invited by their physician to take part in a survey to assess their experiences and satisfaction with treatment. The patient survey aimed to enroll at least 200 patients with DED - around $70 \%$ current users and $30 \%$ patients who had undergone a treatment change from CYC or from LIF in the past 6 months. Treatment change could be from either CYC or LIF to other drugs, or from CYC to LIF or LIF to CYC. Patients were required to provide written, informed consent prior to being enrolled in the study.

\section{Survey}

A survey was developed to elicit patients' perspectives on treatment with either CYC or LIF. Each patient was asked to rate his or her experiences with their current treatment (CYC or LIF) over three domains: satisfaction, frequency of side effects, and limited activities. Items in the satisfaction domain included onset of action, effectiveness of the drug after onset, and ease of use (relating to the dosing and packaging), each rated on a 5-point scale from 1 ("Very dissatisfied") to 5 ("Very satisfied"). Items in the 
frequency of side effects domain included burning sensation, itching, altered sensation of taste (dysgeusia), blurred vision, and discharge, each rated on a 5-point scale from 1 ("Always") to 5 ("Never"). Patients were also able to specify other side effects not listed. The activities domain asked whether patients were limited by DED in their daily lives while on medication with respect to reading, driving, working on the computer, watching TV, work productivity, and social activities, rated on a 5-point scale from 1 ("Always") to 5 ("Never"). If any activity was not applicable to the patient (e.g. if they were retired or out of work), they were able to rate the activity 0 ("I do not do this activity").

A subset of patients who recently switched from CYC or from LIF (within the past 6 months) were also asked to rate the importance of possible reasons for switching. Reasons included inability to relieve dry eye symptoms, onset of action, effectiveness of the drug after onset, ease of use, limited visual tasking activities while on medication, and recommendation from their doctor. Patients were also able to specify their own reasons for switching. A 5-point scale was used, from 1 ("Not important at all") to 5 ("Extremely important").

\section{Analysis}

Patient demographics and responses were examined descriptively. Responses on the 5-point scales were converted to a 3-point scale by combining the two least favorable categories (e.g., very dissatisfied and somewhat dissatisfied) and the two most favorable categories (e.g., very satisfied and somewhat satisfied) (Table 1). Continuous measures were presented as means and standard deviations (SD); categorical measures were presented as counts and percentages.

\section{Results}

\section{Patient Characteristics}

A total of 211 patients were referred by 21 physicians (13 general ophthalmologists, 4 optometrists, and 4 corneal specialists). Of these, 207 (98.1\%) participated in the survey: 98 were current users of CYC (22 recently switched from LIF), 96 were current users of LIF (26 recently switched from $\mathrm{CYC}$ ), and 13 were former users of CYC $(n=4)$ or LIF $(n=9)$ who were switched to other treatments for DED (Table 2). Current users of CYC were older on average than current users of LIF (mean age: 58 vs 55 years), and had a longer duration on their current treatment $(41 \%$ had been using CYC for $>12$ months, compared with $26 \%$ for LIF) (Table 3 ).

\section{Treatment Satisfaction}

Treatment satisfaction was lowest for onset of effect: $51 \%$ of current CYC users and $63 \%$ of current LIF users reported being satisfied (grouped responses of "somewhat satisfied" or "very satisfied") with time to onset of effect (Figure 1). The majority of patients (78\% of current CYC users and $77 \%$ of current LIF users) were satisfied with the ability of CYC and LIF to manage DED after onset of effect. Satisfaction with ease of use was 78\% among current CYC users and 72\% among current LIF users. Few patients reported being "very dissatisfied" with any of the three criteria. The highest proportion of patients who were "somewhat dissatisfied" or "very dissatisfied" was reported for time to onset of effect (29\% and $11 \%$ of current users of CYC and LIF, respectively).

\section{Side Effects}

Burning sensation was the most frequently reported side effect of treatment: $21 \%$ of current CYC users and $22 \%$ of current LIF users "always" or "usually" experienced a burning sensation on instillation (Figure 2). Consistent with the known side effects of LIF, 29\% of current users "always" or "usually" experienced dysgeusia; only $3 \%$ of current CYC users reported the same outcome. Over half of current CYC users (54\%) reported "never" experiencing dysgeusia, compared with $23 \%$ of current LIF users. Blurred vision "always" or "usually" occurred upon instillation in $16 \%$ of current LIF users and $4 \%$ of current CYC users; $50 \%$ of current LIF users and $63 \%$ of current CYC users said they "rarely" or "never" experienced blurred vision. Itching and discharge were the least frequently reported side effects. The majority of patients in both treatment groups "rarely" or "never" itching or discharge: $57 \%$ and $72 \%$ of current CYC users and $56 \%$ and $70 \%$ of current LIF users, respectively.

\section{Activity Limitations}

Working on the computer was the activity most frequently limited by dry eye while on medication: $8 \%$ of current CYC users and $11 \%$ of current LIF users reported "always" or "usually" being limited (Figure 3). Reading was the second most frequently limited activity; $8 \%$ of current CYC users and 7\% of current LIF users reported "always" or "usually" being limited. Around half of patients reported that reading and working on the 
Table I Survey Design

\begin{tabular}{|c|c|c|c|}
\hline Domain & Items & 5-Point Scale & Modified 3-Point Scale \\
\hline I. Satisfaction & $\begin{array}{l}\text { I. Onset of action } \\
\text { 2. Effectiveness of the drug after onset } \\
\text { 3. Ease of use }\end{array}$ & $\begin{array}{l}\text { I. Very dissatisfied } \\
\text { 2. Somewhat dissatisfied } \\
\text { 3. Neither satisfied nor dissatisfied } \\
\text { 4. Somewhat satisfied } \\
\text { 5. Very satisfied }\end{array}$ & $\begin{array}{l}\text { I. Somewhat or very dissatisfied } \\
\text { 2. Neither satisfied nor dissatisfied } \\
\text { 3. Somewhat or very satisfied }\end{array}$ \\
\hline II. Side effects & $\begin{array}{l}\text { I. Burning sensation } \\
\text { 2. Itching } \\
\text { 3. Altered sensation of taste } \\
\text { 4. Blurred vision } \\
\text { 5. Discharge }\end{array}$ & $\begin{array}{l}\text { I. Always } \\
\text { 2. Usually } \\
\text { 3. Sometimes } \\
\text { 4. Rarely } \\
\text { 5. Never }\end{array}$ & $\begin{array}{l}\text { I. Always or usually } \\
\text { 2. Sometimes } \\
\text { 3. Rarely or never }\end{array}$ \\
\hline III. Limited activities & $\begin{array}{l}\text { I. Reading } \\
\text { 2. Driving } \\
\text { 3. Working on computer } \\
\text { 4. Watching TV } \\
\text { 5. Work productivity } \\
\text { 6. Social activities }\end{array}$ & $\begin{array}{l}\text { I. Always } \\
\text { 2. Usually } \\
\text { 3. Sometimes } \\
\text { 4. Rarely } \\
\text { 5. Never }\end{array}$ & $\begin{array}{l}\text { I. Always or usually } \\
\text { 2. Sometimes } \\
\text { 3. Rarely or never }\end{array}$ \\
\hline IV. Switch reasons & $\begin{array}{l}\text { I. Inability to relieve dry eye symptoms } \\
\text { 2. Onset of action } \\
\text { 3. Effectiveness of the drug after onset } \\
\text { 4. Ease of use } \\
\text { 5. Side effect profile } \\
\text { 6. Limited visual tasking activities while } \\
\text { on medication } \\
\text { 7. Recommended by your doctor }\end{array}$ & $\begin{array}{l}\text { I. Insignificant } \\
\text { 2. Somewhat significant } \\
\text { 3. Significant } \\
\text { 4. Highly significant } \\
\text { 5. Very highly significant }\end{array}$ & $\begin{array}{l}\text { I. Insignificant or somewhat insignificant } \\
\text { 2. Significant } \\
\text { 3. Highly or very highly significant }\end{array}$ \\
\hline
\end{tabular}

computer were "rarely" or "never" limited by dry eye while on medication $(51 \%$ and $55 \%$ of current CYC users and $54 \%$ and $49 \%$ of current LIF users, respectively). For the other activities included in the survey (driving, watching TV, work productivity, and social activities) the majority of patients reported "rarely" or "never" being limited by dry eye while on medication (70-94\% of current CYC users and 69-91\% of current LIF users), with driving most often affected and social activities least often affected.

\section{Reasons for Switching}

Of the seven possible reasons for switching provided in the survey, doctor recommendation most strongly influenced patients' decision to switch from CYC or from LIF: $79 \%$ of patients who switched from CYC $(n=23)$ and $77 \%$ of patients who switched from LIF $(n=24)$ rated doctor recommendation as "very important" or "extremely important" (Figure 4). Inability of CYC or LIF to relieve dry eye symptoms was the second most highly rated contributing factor for both groups of switched patients. Patients switched from CYC more frequently rated onset of effect, effectiveness of the drug after onset of effect, and limited activities as "very important" or "extremely important" reasons for switching than did patients switched from LIF. Patients switched from LIF rated the importance of side effect profile more highly than patients switched from CYC; however, 16 patients (6 [20\%] in the switched from CYC group and 10 [32\%] in the switched from LIF group) did not provide a rating for the side effect profile domain.

\section{Discussion}

In this cross-sectional study, we aimed to evaluate patient perspectives on treatment with CYC and LIF. To our knowledge, this is the first real-world survey to comprehensively assess treatment satisfaction, frequency of side effects, and activity limitations in patients using topical anti-inflammatory medications for DED. Although almost $80 \%$ of patients were satisfied with CYC and LIF for continued management of dry eye symptoms, the slow 
Table 2 Patient Distribution

\begin{tabular}{|l|l|l|l|l|l|}
\hline \multicolumn{2}{|c|}{} & \multicolumn{2}{l|}{ Current Prescription Treatment for DED } & \multirow{2}{*}{ Total } \\
\cline { 3 - 6 } \multicolumn{2}{|l|}{} & CYC & LIF & Others & \\
\hline Prior prescription treatment for DED & None & 76 & 70 & - & \\
& CYC & - & 26 & 4 & $\begin{array}{l}30 \text { (Switched from CYC) } \\
\text { LII (Switched from LIF) }\end{array}$ \\
\hline \multirow{2}{*}{ Total } & LIF & 22 & - & 9 & \\
\hline
\end{tabular}

Abbreviations: CYC, cyclosporine ophthalmic emulsion 0.05\%; DED, dry eye disease; LIF, lifitegrast ophthalmic solution $5 \%$.

Table 3 Patient Characteristics

\begin{tabular}{|c|c|c|c|c|}
\hline $\begin{array}{l}\text { Patient } \\
\text { Characteristics }\end{array}$ & $\begin{array}{l}\text { Current CYC User } \\
(\mathrm{N}=98)\end{array}$ & $\begin{array}{l}\text { Current LIF User } \\
(\mathrm{N}=96)\end{array}$ & $\begin{array}{l}\text { Switched from CYC } \\
(\mathrm{N}=30)\end{array}$ & $\begin{array}{l}\text { Switched from LIF } \\
(N=31)\end{array}$ \\
\hline Age, mean years $(\mathrm{SD})$ & $58.2(15.7)$ & $55.2(14.3)$ & $57.0(14.6)$ & $56.5(14.8)$ \\
\hline \multicolumn{5}{|c|}{ Age group (years), n (\%) } \\
\hline $18-39$ & $12(12)$ & $18(19)$ & $6(20)$ & $4(13)$ \\
\hline $40-59$ & $34(35)$ & $4 \mathrm{I}(43)$ & $13(43)$ & $12(39)$ \\
\hline$\geq 60$ & $52(53)$ & $37(39)$ & II (37) & $15(48)$ \\
\hline \multicolumn{5}{|l|}{ Gender, n (\%) } \\
\hline Female & $79(8 \mathrm{I})$ & $75(78)$ & $22(73)$ & $23(74)$ \\
\hline Male & $19(19)$ & $21(22)$ & $8(27)$ & $8(26)$ \\
\hline \multicolumn{5}{|c|}{ Duration on current treatment, $\mathrm{n}(\%)$} \\
\hline$<1$ month & $5(5)$ & $6(6)$ & $4(13)$ & $6(20)$ \\
\hline I-3 months & $12(12)$ & $14(15)$ & $2(7)$ & $2(7)$ \\
\hline $4-6$ months & $24(24)$ & $28(29)$ & $10(33)$ & $9(30)$ \\
\hline $7-12$ months & $17(17)$ & $23(24)$ & $10(33)$ & $9(30)$ \\
\hline$>12$ months & $40(4 I)$ & $25(26)$ & $4(13)$ & $5(17)$ \\
\hline
\end{tabular}

Abbreviations: CYC, cyclosporine ophthalmic emulsion $0.05 \%$; LIF, lifitegrast ophthalmic solution 5\%; SD, standard deviation.

onset of effect of CYC, and to a lesser extent of LIF, was viewed unfavorably by current users. Working on the computer and reading were the most affected activities among patients with DED. Patient responses for the side effects domain were consistent with the known tolerability issues of CYC and LIF. ${ }^{15,16}$ Burning sensation was "always" or "usually" experienced by approximately one in four patients upon treatment instillation. Notably, among current LIF users, the frequency of dysgeusia was substantially higher in this real-world cohort than in the pooled analysis of five LIF clinical trials. ${ }^{16}$

DED is a complex and chronic disease triggered and exacerbated by inflammation and damage to the ocular surface that disturbs the dynamic equilibrium of the lacrimal functional unit, resulting in tear film instability and a range of ocular symptoms. The detrimental impact on visual function and QoL is substantial and can interfere with a patient's ability to effectively carry out everyday activities. ${ }^{6,22}$ DED represents a growing global public health problem. Although the exact prevalence of DED is hard to measure due to differences in diagnostic methods ${ }^{23}$ and lack of correlation between clinical measures and patient-reported symptoms, ${ }^{24-26}$ the aging population and our increasing reliance upon digital devices are contributing to a rise in the number of people living with a DED diagnosis. Several studies have established that long durations of computer and smartphone use can trigger and/or exacerbate dry eye symptoms across all age groups. ${ }^{27-30}$ It is not unusual now for adults to spend more time looking at screens than sleeping. ${ }^{31}$ Thus, whereas in the past the typical patient 


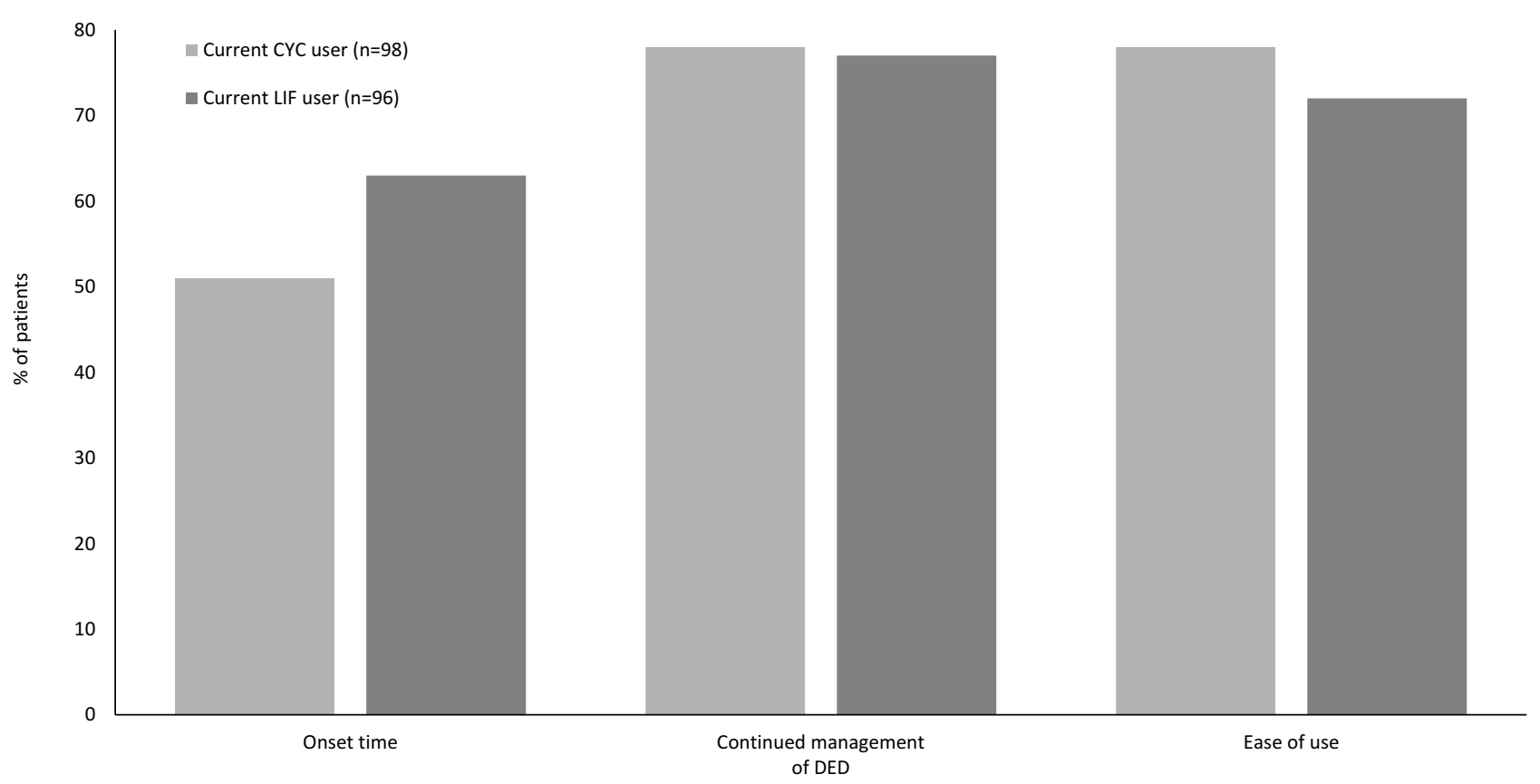

Figure I Percentage of patients who reported being "somewhat satisfied" or "very satisfied" with their current treatment. Abbreviations: CYC, cyclosporine ophthalmic emulsion $0.05 \%$; DED, dry eye disease; LIF, lifitegrast ophthalmic solution $5 \%$.

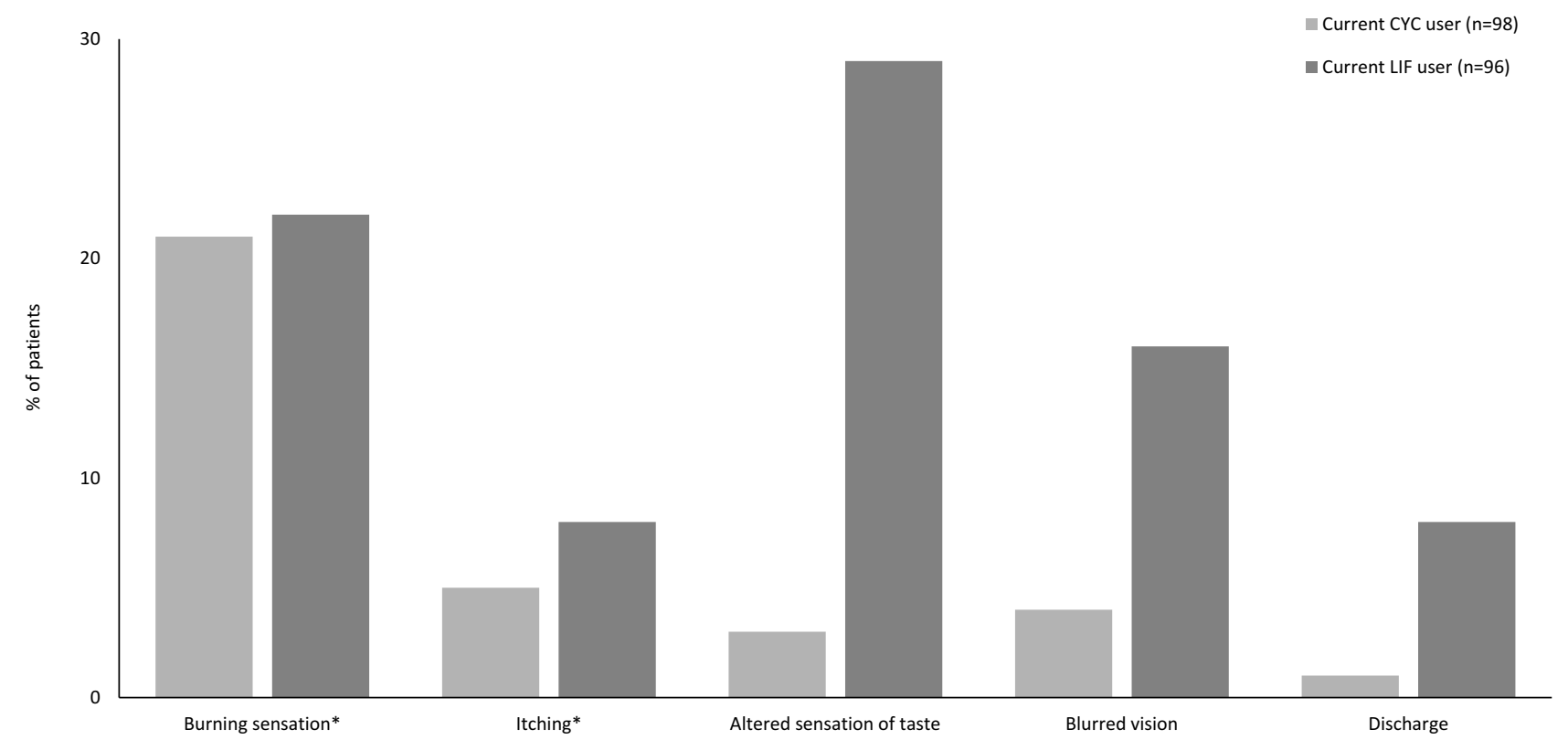

Figure 2 Percentage of patients who reported always' or "usually" experiencing side effects while on their current treatment. Note: *One patient in the current LIF user group did not provide a response for this category.

Abbreviations: CYC, cyclosporine ophthalmic emulsion 0.05\%; LIF, lifitegrast ophthalmic solution $5 \%$.

with DED was likely to be a woman aged over 50 years, ${ }^{6}$ ophthalmologists can now expect to see younger patients of both sexes with "lifestyle-driven" DED. ${ }^{32,33}$

Although this survey did not directly evaluate treatment persistence, it is worth noting that $31 \%$ of CYC users and $40 \%$ of LIF users had been on their current treatment for 6 months or less. The implications of this should be considered when interpreting the results, given that CYC can take as long as 3-6 months of continued twice-daily use to work, and that good compliance and persistence with CYC have been associated with greater treatment satisfaction in a larger patient sample. ${ }^{18}$ 


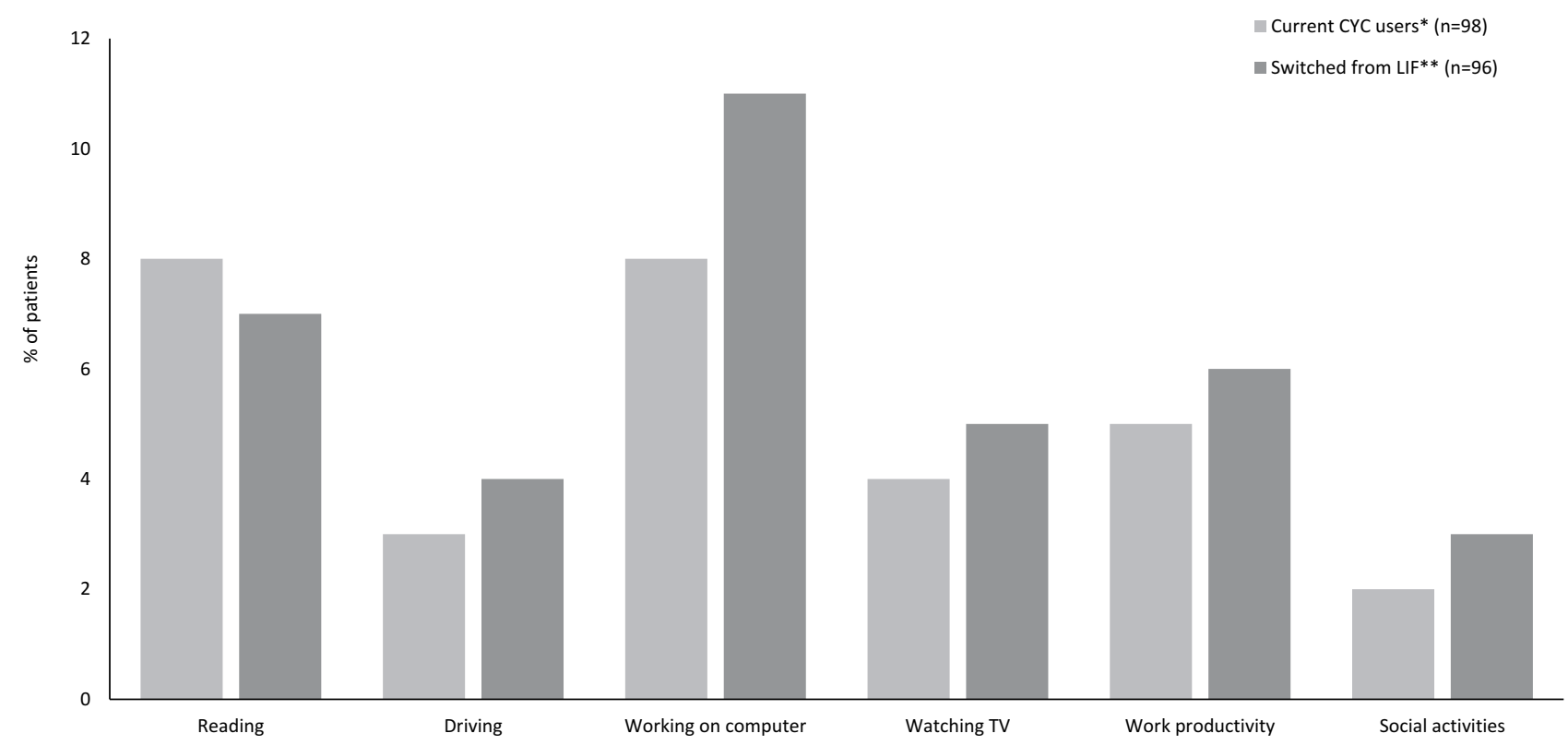

Figure 3 Percentage of patients who reported that they "always" or "usually" experienced activity limitation while on their current treatment.

Notes: *An alternate response of "I do not do this activity" was provided by I patient for "Reading", 'Driving', and "Social activities", and 5 patients for "Working on computer" and "Work productivity": **An alternate response of "I do not do this activity" was provided by I patient for "Reading", 2 patients for "Driving", 5 patients for "Working on computer", and 7 patients for "Work productivity".

Abbreviations: CYC, cyclosporine ophthalmic emulsion $0.05 \%$; LIF, lifitegrast ophthalmic solution $5 \%$.

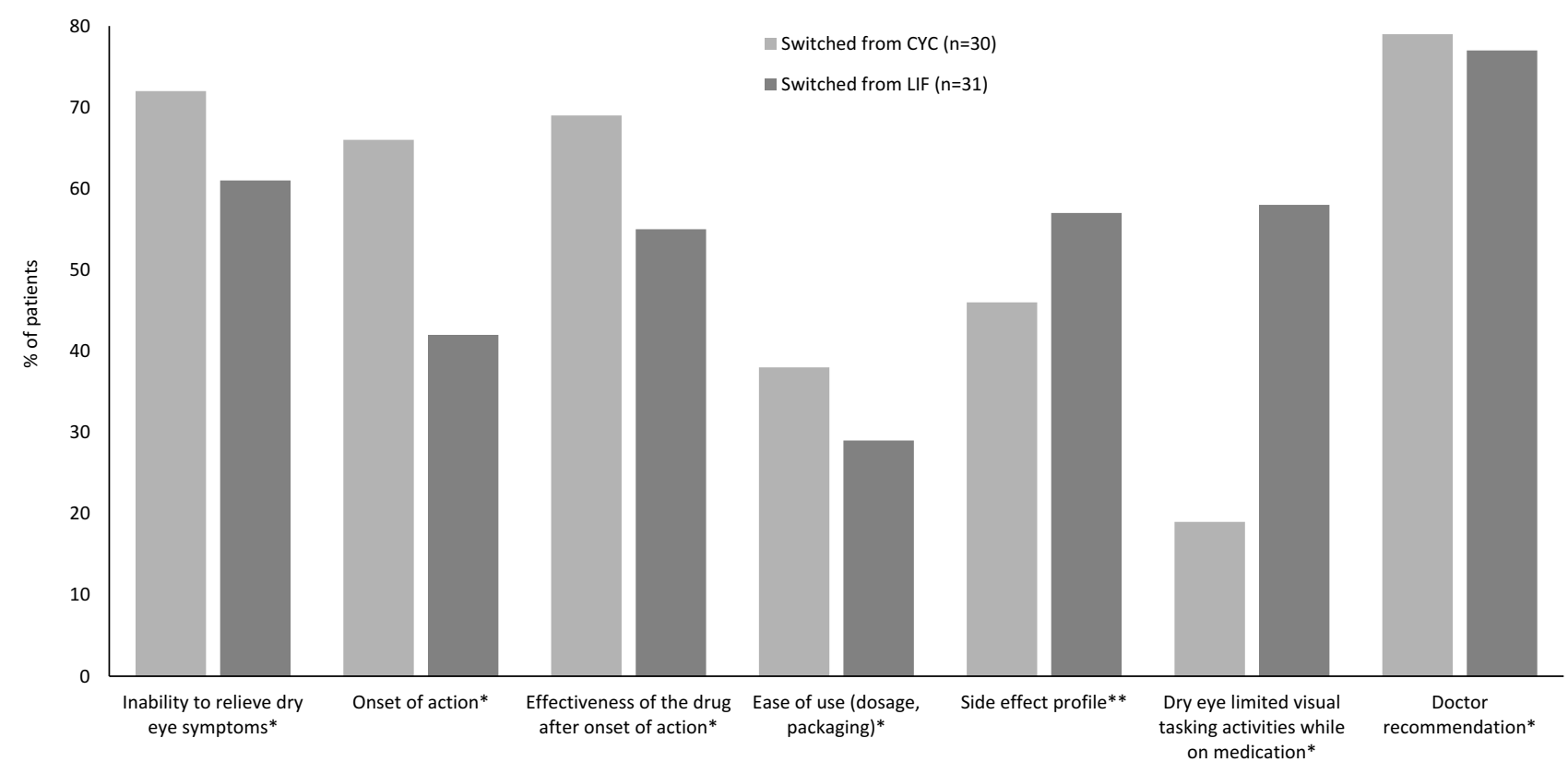

Figure 4 Percentage of patients who rated reasons for switching from CYC or LIF as "very important" or "extremely important".

Notes: *No response was provided in this category by I patient in the switched from CYC group; **No response was provided in this category by 5 patients in the switched from CYC group and 10 patients in the switched from LIF group.

Abbreviations: CYC, cyclosporine ophthalmic emulsion $0.05 \%$; LIF, lifitegrast ophthalmic solution $5 \%$.

Despite the many challenges in the management of DED, disease control is possible with long-term use of topical anti-inflammatory agents, in accordance with current treatment guidelines. However, the patient-perceived gaps in dry eye management identified in this study demonstrate a need for additional options for long-term treatment of DED. In August 2018, a nanomicellar cyclosporine ophthalmic solution $0.09 \%$ was approved in the US 
for the indication of increasing tear production in patients with DED. ${ }^{34-36}$ A mucus-penetrating particle (MPP) formulation of loteprednol etabonate is currently in late-stage development for DED, with two completed Phase III trials and a third underway. ${ }^{37}$ The arrival of new treatment options may help address some of the current unmet needs of patients with DED.

This study has some limitations. First, there was the potential for selection bias, because patients were referred by physicians who considered them appropriate for participation and inclusion criteria were broad. The sample may therefore not be representative of the general population of patients with DED who use CYC or LIF. Second, the severity of dry eye and duration of disease was not assessed at baseline, and patient compliance with medication was not followed. The influence of disease characteristics and treatment compliance on patient experiences is therefore unclear. Third, the number of patients who recently switched from CYC or LIF was relatively small and $20-27 \%$ of switched patients had been on their current treatment for 3 months or less, which may not have been long enough to properly evaluate patient satisfaction (especially with respect to time to onset of action). Finally, the survey was designed as a descriptive study and no formal comparisons between the two treatments were performed. It is possible that patients who were recently switched to CYC or LIF may have had some difficulty distinguishing between side effects of the medication and common symptoms of DED (ocular discomfort, visual disturbance, and dryness); however, treatmentemergent adverse events in this study appear to be consistent with the known safety profiles of CYC and LIF observed in clinical trials. ${ }^{12,13}$

\section{Conclusions}

In a cross-sectional survey study, patients with DED treated with non-steroidal anti-inflammatory medications were often unable to achieve effective symptom relief. For both CYC and LIF, onset of effect was viewed unfavorably by a substantial proportion of patients, and side effects were commonly experienced. These results indicate a need among patients with DED for additional treatment options to help them manage their disease.

\section{Acknowledgments}

The authors thank Alan Pedder, MSc, for writing assistance.

\section{Funding}

This study was sponsored by Sun Pharmaceutical Industries, Inc. (Princeton, NJ, USA).

\section{Disclosure}

Dr. Darrell E White is speaker for and reports personal fees from Sun Pharmaceuticals, Allergan, and Takeda/Novartis, outside the submitted work. Dr. Yang Zhao, Dr. Abayomi Ogundele are employees of Sun Pharmaceutical Industries, Inc. Hemalatha Jayapalan, Pattabhi Machiraju, and Ramu Periyasamy are affiliated with Indegene Inc. The authors report no other conflicts of interest in this work.

\section{References}

1. Farrand KF, Fridman M, Stillman IÖ, et al. Prevalence of diagnosed dry eye disease in the United States among adults aged 18 years and older. Am J Ophthalmol. 2017;182:90-98. doi:10.1016/j.ajo.2017.06.033

2. Messmer EM. The pathophysiology, diagnosis, and treatment of dry eye disease. Dtsch Arztebl Int. 2015;112:71-81. doi:10.3238/ arztebl.2015.0071

3. Nelson JD, Craig JP, Akpek EK, et al. TFOS DEWS II Introduction. Ocul Surf. 2017;15(3):269-275. doi:10.1016/j.jtos.2017.05.005

4. Craig JP, Nichols KK, Akpek EK, et al. TFOS DEWS II definition and classification report. Ocul Surf. 2017;15(3):276-283. doi:10.1016/j.jtos.2017.05.008

5. Saldanha IJ, Petris R, Han G, et al. Research questions and outcomes prioritized by patients with dry eye. JAMA Ophthalmol. 2018;136:1179. doi:10.1001/jamaophthalmol.2018.3352

6. Miljanovic B, Dana R, Sullivan DA, et al. Impact of dry eye syndrome on vision-related quality of life. Am J Ophthalmol. 2007;143:409-415. doi:10.1016/j.ajo.2006.11.060

7. Kawashima M, Uchino M, Yokoi N, et al. The association of sleep quality with dry eye disease: the Osaka study. Clin Ophthalmol. 2016;10:1015-1021. doi:10.2147/OPTH

8. Patel VD, Watanabe JH, Strauss JA, et al. Work productivity loss in patients with dry eye disease: an online survey. Curr Med Res Opin. 2011;27:1041-1048. doi:10.1185/03007995.2011.566264

9. Uchino M, Uchino Y, Dogru M, et al. Dry eye disease and work productivity loss in visual display users: the Osaka study. $\mathrm{Am}$ J Ophthalmol. 2014;157:294-300. doi:10.1016/j.ajo.2013.10.014

10. Jones L, Downie LE, Korb D, et al. TFOS DEWS II management and therapy report. Ocul Surf. 2017;15:575-628. doi:10.1016/j.jtos.2017.05.006

11. Behrens A, Doyle JJ, Stern L, et al. Dysfunctional tear syndrome: a Delphi approach to treatment recommendations. Cornea. 2006;25:900-907. doi:10.1097/01.ico.0000214802.40313.fa

12. Restasis (cyclosporine ophthalmic emulsion $0.05 \%$ ) approval package. Available from: www.accessdata.fda.gov/drugsatfda_docs/nda/2003/ 21-023_Restasis_Approv.pdf. Accessed September 17, 2019.

13. Novartis Pharmaceuticals Corporation. Xiidra (Lifitegrast Ophthalmic Solution 5\%) [Package Insert]. East Hanover, NJ: Novartis Pharmaceuticals Corporation, November 2019.

14. Akpek EK, Amescua G, Farid M, et al. American academy of ophthalmology preferred practice pattern cornea and external disease panel. Dry eye syndrome preferred practice pattern ${ }^{\circledR}$. Ophthalmology. 2019;126:P286-P334. doi:10.1016/j.ophtha.2018.10.023

15. Sall K, Stevenson OD, Mundorf TK, et al. Two multicenter, randomized studies of the efficacy and safety of cyclosporine ophthalmic emulsion in moderate to severe dry eye disease. CsA phase 3 study group. Ophthalmology. 2000;107:631-639. doi:10.1016/S01616420(99)00176-1 
16. Nichols KK, Donnenfeld ED, Karpecki PM, et al. Safety and tolerability of lifitegrast ophthalmic solution $5.0 \%$ : pooled analysis of five randomized controlled trials in dry eye disease. Eur J Ophthalmol. 2019;29:394-401. doi:10.1177/1120672118791936

17. Barber LD, Pflugfelder SC, Tauber J, et al. Phase III safety evaluation of cyclosporine $0.1 \%$ ophthalmic emulsion administered twice daily to dry eye disease patients for up to 3 years. Ophthalmology. 2005;112:1790-1794. doi:10.1016/j.ophtha.2005.05.013

18. Trattler W, Katsev D, Kerney D. Self-reported compliance with topical cyclosporine emulsion $0.05 \%$ and onset of the effects of increased tear production as assessed through patient surveys. Clin Ther. 2006;28:1848-1856. doi:10.1016/j.clinthera.2006.11.016

19. Byun YS, Rho CR, Cho K, et al. Cyclosporine $0.05 \%$ ophthalmic emulsion for dry eye in Korea: a prospective, multicenter, open-label, surveillance study. Korean $J$ Ophthalmol. 2011;25:369-374. doi:10.3341/kjo.2011.25.6.369

20. Pepose JS, Qazi M, Devries DK. Longitudinal changes in dry eye symptoms and signs following lifitegrast therapy and relationship to tear osmolarity. Clin Ophthalmol. 2019;13:571-579. doi:10.2147/ OPTH.S196593

21. Donnenfeld ED, Karpecki PM, Majmudar PA, et al. Safety of lifitegrast ophthalmic solution $5.0 \%$ in patients with dry eye disease: a 1-year, multicenter, randomized, placebo-controlled study. Cornea. 2016;35:741-748. doi:10.1097/ICO.0000000000000803

22. Li M, Gong L, Chapin WJ, et al. Assessment of vision-related quality of life in dry eye patients. Invest Ophthalmol Vis Sci. 2012;53:5722-5727. doi:10.1167/iovs.11-9094

23. Thulasi P, Djalilian AR. Update in current diagnostics and therapeutics of dry eye disease. Ophthalmology. 2017;124:S27-S33. doi:10.1016/j.ophtha.2017.07.022

24. Galor A, Felix ER, Feuer W, et al. Dry eye symptoms align more closely to non-ocular conditions than to tear film parameters. $\mathrm{Br}$ J Ophthalmol. 2015;99:1126-1129. doi:10.1136/bjophthalmol-2014306481

25. Hua R, Yao K, Hu Y, et al. Discrepancy between subjectively reported symptoms and objectively measured clinical findings in dry eye: a population based analysis. BMJ Open. 2014;4:e005296. doi:10.1136/bmjopen-2014-005296

26. Gomes JAP, Santo RM. The impact of dry eye disease treatment on patient satisfaction and quality of life: a review. Ocul Surf. 2019;17:9-19. doi:10.1016/j.jtos.2018.11.003
27. Moschos MM, Chatziralli IP, Siasou G, et al. Visual problems in young adults due to computer use. Klin Monbl Augenheilkd. 2012;229:379-381. doi:10.1055/s-0031-1299222

28. Ribelles A, Galbis-Estrada C, Parras MA, et al. Ocular surface and tear film changes in older women working with computers. Biomed Res Int. 2015;2015:467039.

29. Moon JH, Kim KW, Moon NJ. Smartphone use is a risk factor for pediatric dry eye disease according to region and age: a case control study. BMC Ophthalmol. 2016;16:188. doi:10.1186/s12886-0160364-4

30. Jaiswal S, Asper L, Long J, et al. Ocular and visual discomfort associated with smartphones, tablets and computers: what we do and do not know. Clin Exp Optom. 2019;102:463-477. doi:10.1111/ cxo.v102.5

31. Ofcom Communications Market Report 2016. Available from: www. ofcom.org.uk/research-and-data/multi-sector-research/cmr/cmr16. Accessed September 17, 2019.

32. Sheppard AL, Wolffsohn JS. Digital eye strain: prevalence, measurement and amelioration. BMJ Open Ophthalmol. 2018;3:e000146. doi:10.1136/bmjophth-2018-000146

33. Courtin R, Pereira B, Naughton G, et al. Prevalence of dry eye disease in visual display terminal workers: a systematic review and meta-analysis. BMJ Open. 2016;6:e009675. doi:10.1136/bmjopen2015-009675

34. Karpecki PM, Weiss SL, Kramer WG, et al. A Phase 1, open-label, single-arm study evaluating the ocular safety of OTX-101 and systemic absorption of cyclosporine in healthy human volunteers. Clin Ophthalmol. 2019;13:591-596. doi:10.2147/OPTH.S187945

35. Mandal A, Gote V, Pal D, et al. Ocular pharmacokinetics of a topical ophthalmic nanomicellar solution of cyclosporine (Cequa ${ }^{\circledR}$ ) for dry eye disease. Pharm Res. 2019;36:36. doi:10.1007/s11095-018-2556-5

36. Goldberg DF, Malhotra RP, Schechter BA, et al. A Phase 3, randomized, double-masked study of OTX-101 ophthalmic solution $0.09 \%$ in the treatment of dry eye disease. Ophthalmology. 2019;126:1230-1237. doi:10.1016/j.ophtha.2019.03.050

37. Kala Pharmaceuticals press release. August 8, 2019. Kala pharmaceuticals receives FDA complete response letter for KPI-121 $0.25 \%$ NDA and plans to respond with data from STRIDE 3 trial. Available from: http://investors.kalarx.com/news-releases/news-release-details /kala-pharmaceuticals-receives-fda-complete-response-letter-kpi. Accessed January 2, 2020.
Clinical Ophthalmology

\section{Publish your work in this journal}

Clinical Ophthalmology is an international, peer-reviewed journal covering all subspecialties within ophthalmology. Key topics include: Optometry; Visual science; Pharmacology and drug therapy in eye diseases; Basic Sciences; Primary and Secondary eye care; Patient Safety and Quality of Care Improvements. This journal is indexed on PubMed
Dovepress

Central and CAS, and is the official journal of The Society of Clinical Ophthalmology (SCO). The manuscript management system is completely online and includes a very quick and fair peer-review system, which is all easy to use. Visit http://www.dovepress.com/ testimonials.php to read real quotes from published authors. 